\title{
A Critical Case Study: Examining the Self-Identity and Self-Efficacy of Afro-Brazilian Teachers
}

\author{
Kellee D. Jenkins, Ph.D. \\ Howard University \\ School of Education \\ $24414^{\text {th }}$ Street, NW \\ Washington, D.C. 20059 \\ USA
}

\begin{abstract}
Grounded in Freire's critical pedagogy, this article highlights the journey of Afro-Brazilian teachers who teach marginalized populations by examining how their process of self-identity and efficacy informed their literacy practices and instructional decision-making. Using case study research methodology, this article examines how Afro-Brazilian teachers convey and enact their educational, social, and cultural experiences to develop selfidentity and self-efficacy as educators. This paper draws heavily on the social and historical perspectives that contribute to the realities of the Afro-Brazilian teacher and their often-marginalized populations they teach.

Hence, the phenomenological nature of the study suggests diverse implications for not only Afro-Brazilian teachers, but also Brazilian schools and society.
\end{abstract}

Keywords: Afro-Brazilian, Critical Pedagogy, Teacher Education, Literacy, Global Citizenship, Community Empowerment

\section{Introduction}

Current research shows that the lack of advanced literacy skills continue to be one of the most pressing challenges in education (Moje, 2000 ; Shanahan \& Shanahan, 2008). Emphasizing critical literacy is a suggested pedagogical approach in education used to address and improve literacy instruction and learning, particularly in groups of students who are of color, who are identified as a racial minority group, and/or who come from marginalized populations (Freire, 1993; Freire \& Macedo, 1987).

However, the majority of mainstream approaches in education focuses on teaching literacy as a basic skill and fails to take into consideration the cultural background and individual needs of students. This practice translates into a system of education that does not prepare students to move beyond the status quo in developing the much critical literacy needed to fulfill multiple roles in society. Within the critical pedagogy framework, teachers and students are cognizant of different kinds of literacy that are needed for life at home, work, school, politics, and the community (NCSALL, 2007).

\section{Historical Perspective \& Context}

Brazil is notorious for its high inequality and poverty levels, even by Latin American Standards. Arguably, the most striking features of income inequality in Brazil is the large socioeconomic discrepancy between population groups based on color. Brazil's history regarding race and education continues to be debated with many theories abounding about the status of race relations and educational success. The racial democracy theory is widely accepted, by Brazilians and others around the world, and purports the absence of racial tensions and disenfranchisement. The concept of a racial democracy prevailed primarily because Brazil, unlike other countries such as the United States' segregation and South Africa's apartheid, had no laws or policies that were specific to race (Htun, 2004; Telles, 2007). Instead, Brazilians view themselves as an exemplar of a multiracial and multicultural society with any educational, economic, or social disparities between races being attributed to issues of class. As such, one identifies his or herself as Brazilian rather than Afro-Brazilian or European-Brazilian.

Brazilians whom view themselves as a racial democracy fail to remember its tumultuous history of slavery and dictatorship that staggered the country's economic progress for decades. 
Brazil imported the largest number of enslaved Africans, was one of the last countries to abolish slavery, and suppressed freedom of speech and political opposition during a military dictatorship. As a result, the country suffered from high rates of poverty, illiteracy, and a weak economy, (IBGE, 2010). Additionally, Brazil lost its voice with many fearing to speak freely or honestly on polarizing topics such as race.

While the contentious debate between racism and classism still exist, many Brazilians now acknowledge the possibility or trace racial discrimination. Census data identifies that half of the population consists of entirely of Afro-Brazilians who earn half of the income of their white counterparts in comparable professions (Telles, 2004; IBGE, 2010). Furthermore, Afro- Brazilians have had the least access to education. Prior to the implementation of racial quotas in 2004, non-white Brazilians rarely attended universities (Racusen, 2009). The remnants of Brazil's racial history are evident in the access of Afro-Brazilian students' access to school and the development and training of Afro-Brazilian teachers. As a result, national efforts to implement a variety of initiatives to address the inequalities that disproportionately affect Afro- Brazilians, including mandates to teach Afro-Brazilian history in schools and funding economically disadvantage students to pursue degrees at universities, have become more prominent in the Brazilian educational system (Ekey, 2010).

\section{Theoretical Framework: Critical Pedagogy}

The Critical Pedagogy framework provides theoretically situates this work and includes the intersections between literacy, language, and culture. Stemming from the work of Paulo Freire, an educator philosopher who believed that education should promote cultural relevance of students and empower them as participatory social change agents within their schools and communities, critical pedagogy supports the idea of teachers and students engaging in critical dialogue in order to create progressive social change. The Freirean pedagogical approach to education has remained a relevant component of education in the United States and Latin America (Bartlett, 2005).

Furthermore, Critical Pedagogy asserts that learning is socially constructed and is rooted deeply in one's race, language, ethnicity, and culture. From this perspective, education values the social and cultural backgrounds of students. Thus, critical pedagogy is of the upmost importance because it emphasizes the philosophy of preparing teachers to help students understand how to use their literacy skills to analyze and transform their educational and social positions in society. Emphasizing a contextualized culturally relevant lens, the Critical Pedagogy framework allows one to examine his/her level of literacy and the role that literacy plays in his/her community (Auerbach, 1989; Lankshear \& McLaren, 1993). Since critical literacy learning involves teachers and students engaging in a dialogic relationship that encourages students to use their literacy skills to analyze their position in society, teachers must create a democratic classroom that takes into account the cultural, social, and academic needs of students (Freire, 1993). As a result, teachers support students by creating and maintaining a classroom that is culturally relevant, student driven, and socially empowering (Freire, 1993; Delpit, 2006; Lee, 2007). Critical literacy learning, therefore, involves teaching students to develop a critical consciousness of how advance literacy skills go well beyond basic reading and writing and can be used to transform their lives and the society in which they live (Shor, 1992; Moje 2000; Freire, 1993). This critical consciousness is of particular importance for people of color who may have a marginalized position in society due to inadequate or lack of access to education, health care, housing, and politics. Thus, the development of critical literacy skills is paramount in understanding how knowledge is produced, obtained, and used to influence various aspects of life and society (Freire, \& Macedo, 1987; Gee, 1993; Delpit, 2006).

\subsection{Critical Pedagogy in Brazil}

Taking into consideration Brazil's history of racial and economic hegemony, the micro-culture exhibited in schools can underscore larger social ills present in society. Hence, teachers have an essential role and responsibility to prepare students not only academically, but socially, culturally, and economically to compete at all levels of society. Arguably, this process begins with the teacher and not the student. How a teacher views his or her own self-efficacy, literacy skills or ability to "read the world" have incredible impact on teachers' instructional competencies in the classroom and hence, students, particularly, students of color, ability to use literacy and the educational experience as tool for empowerment. In Brazil, the promotion of critical pedagogy has resulted in a series of social justice movements that have greatly influenced the education of Afro-Brazilian teachers and subsequently their impact in the classroom and in the lives of students who represent marginalized groups. 
With extreme inequalities in the educational system in Brazil, the idea of promoting progressive social change became a necessity in organizing and growing the Afro consciousness movement that began in the 1930's and still continues today (Ekey, 2010). While the origins of critical pedagogy remained intact for decades, at least in theory, Afro-Brazilians continue to debate and effectively implement the ideas of Freire.

\section{Methodological Approach}

A case study method was used to gain an in-depth understanding of Afro-Brazilians self-identity and efficacy as it relates to their own literacy development and instructional practices. This methodology allows for intensive, holistic, and meaningful description and analysis of the instructional routines and processes of teachers within the real-life context of their work (Merriam, 2002; Yin, 2003). Case studies are a valuable tool that allows for collection of evidence from multiple sources. Analysis of these multiple data sources was deemed necessary to understand how teachers' beliefs and literacy knowledge influence instructional practice. This study employed a phenomenological analysis of narratives from seven Afro-Brazilian teachers. This methodology allows for a deeper understanding of Afro-Brazilian teachers' beliefs, knowledge, and instructional practices as it relates to critical pedagogy within the real-life context (Merriam, 2002; Yin, 2003). Furthermore, each teacher's experiences illustrate how intensive immersion within teachers' schools and communities facilitated rich description of how self-identity impacted their instructional decision making over a period of time (Patton, 2001; Miles \& Huberman, 1994).

\subsection{Context \& Setting of Study}

The context of this study played an important role in understanding what beliefs Afro-Brazilian teachers held regarding their self-identity and self-efficacy as educators and how their beliefs about race and education influenced their instructional decision-making. The setting and participants provided specific cultural and historical information situated in a particular place and time. This study was conducted Salvador da Bahia, Brazil, a large city in Northeast Brazil. The teaching profession in Brazil is its third largest occupation; however, the accreditation of teachers has been a salient issue for many years. Of the 1.5 million teachers in Brazil, roughly half of them have obtained teaching credentials or a degree of higher education; In addition, Brazilian teachers earn \$200 US dollars per month and often work several jobs to survive economically (Barretto, 2015). To address the issue of teacher qualification, the Brazilian government developed incentives to encourage and support teachers in earning a higher education degree in teaching. In 2009, The National Plan for Basic School Teacher Education (PARFOR) was created to provide higher education courses and in-service training for teachers in public education systems (Barretto, 2015). Including several teachers in this study, an opportunity to attend the university, become a certified teacher, and earn a degree of education. Participants in this included two preservice and five in-service teachers who identified themselves as Afro-Brazilian or Moreno (mixed race) and who have teaching experiences in Brazilian schools as well as in community organizations. In addition, five of the eight participants were taking college courses at the Federal University to obtain official teacher certification and/or to earn a degree. In some cases, teachers were working towards an advanced degree.

\subsection{Participants}

A purposeful sampling approach (Patton, 2001) was used to identify teachers who emphasized literacy instruction in discipline specific classes. Teacher selection was based on several criteria: (1) teachers who identified as Black and/or Afro-Brazilian heritage; (2) suggestions from faculty of the federal university; (3) teachers willingness to participate in the research study. The teachers who volunteered to participate in the study represented the major sectors of education including elementary, middle, and high school. Table 1 gives an overview of the participants' demographic background.

\subsection{Data Collection}

To gain an understanding of the relationship among teacher beliefs, knowledge, instructional routines, and contextual factors, two methods of data collection were used: semi structured interviews and classroom observations.

\subsubsection{Interviews}

Marshall and Rossman (2006) state that the primary goal of the interview was to immerse in the natural setting and to "capture the deep meaning of experience in the participants' own words" (p.55). 
Interviews were conducted with eight teachers to ascertain their knowledge and beliefs about their own literacy development and their literacy instruction. Research asserts that teachers' knowledge and beliefs about the functions of critical literacies influence their instructional decisions and practices (Hall, 2005). A semi-structured interview protocol guided the discussion with the teachers. Teacher interviews took approximately 45 minutes. The focus was threefold: (a) cultural and social background information, (b) educational background and (c) instructional information and implementation. The teachers' interview protocol was designed to gain information regarding the historical impact of Brazil's race and education policies on teachers' social, cultural, educational, and professional experiences. Interviews were taped and transcribed verbatim in order to gain an accurate depiction and deep meaning of experiences in the participants' own words. Data from the interviews were analyzed and interpreted based on the participants' responses and the researcher's understanding of what was said. To create meaning from the participants' experiences, the data collected from the interviews were analyzed as they were collected and organized into categories that illustrated the participants' experiences. The study's purpose, the knowledge, and orientation of the research and the meaning of participants' experiences were used to create categories (Nieto, 2006).

\subsubsection{Observations}

For Marshall and Rossman (2006) questionnaires are limited in that they lack the ability to reveal and understand deeply held beliefs and values and they offer, "little value for examining complex social relationships or intricate patterns of interaction" (p.126). Teacher observations were conducted after interviews. They were utilized to validate the accuracy of the participants' responses and to gain a deeper understanding of complex interactions in natural social settings (Marshall \& Rossman, 2006). Observations were also used to explore and describe the instructional repertoire of teachers as well as understand the culture of literacy and various literacy expectations in classrooms. In addition, observations explored how teachers enact their beliefs and knowledge about literacy instruction and Afro-Brazilian history and culture. Table 2 gives an overview of the classroom observation characteristics.

\subsection{Data Analysis}

The data analysis was descriptive in nature and advances to developing categories from recurring themes found within the data. Understanding data collected from interviews consisted of: (a) reading each transcript line by line, (b) studying and identifying key phrases that related directly to the beliefs, knowledge, and integration of literacy instruction, (c) analyzing the meaning of each significant statement or phrase, and (d) organizing key phrases into categories of major themes. Categories were systematically created to answer the study's research questions. The data that were relevant to answering the research questions were placed into specific categories and subcategories. The obtained data were placed into one or more categories to accurately reflect how the participants' understood and made meaning of their experience. This type of qualitative inquiry allowed the researcher to identify major themes and patterns that emerged from the interviews. The meaning and insights from the interview data were used to create a complete understanding of the participants' experiences and contributed to the findings of the study.

\section{Findings}

The research question for this study focused on how Afro-Brazilian teachers' self-identity and self-efficacy in critical literacy influence their instructional decision-making. Data analysis across teachers identified several major themes including self-identity through community empowerment, self-efficacy and the black consciousness, and social justice through literacy development. These sections highlight participant's beliefs about the aforementioned themes and how they intersect and sometimes conflict within the context of the AfroBrazilian's cultural and educational experiences.

\section{1 Self-Identity through Empowered Communities:}

Although community driven and not officially recognized, the education provided by their parents proved crucial for their social and cultural development. Afro-Brazilians who did not come from socially and critically conscious parentage or communities were less likely to have access or success in schools. Thus, participants in the study relied heavily on their communities to develop and establish their sense of identity and later to foster pride and a sense of social engagement with and in their students. One participant describes an early childhood experience that made an impact both personally and professionally. While reminiscently looking at photos, she stated: "This photo is the record of a father's pride for child education. 
I was just as proud of that. The second photo is the first day of school, a precious moment for a simple family like mine. Perhaps many children are proud of the material possessions acquired by their parents, mine is undoubtedly located, in the certainty of love and affection that they dedicated to us when they chose the school as an inheritance. And look, daddy, I've gone too far... thank you, daddy, for the priceless well of the values you've taught me. You planted, sowed, defended, fought, idealized, held, picked... combined well, the verb to live! From his great legacy, you left thirteen honorable men and women who understood your lessons. I'm proud of your teachings... thank you daddy for everything that you represent in our life."

Another participant describes how the family and community have an essential role to play in the education of marginalized communities: "In a way it is not so traditional. As I attend the elementary school that goes from the first to the fifth year and sixth to the ninth, I have children and adolescents with very diverse levels in the care of their education and the issue of knowledge. Often we receive a child who is in the third grade of elementary school and a teenager who is in the ninth grade, but they have an equivalent relation of knowledge. Sometimes the third grade student helps the fifth grade or ninth grade student ... she's bringing here the issue of literacy. The boys in the fifth grade have a literacy process that is still very impoverished. He realizes that world conditions are still very restricted. It cannot seem that some issues are matters that can assist you in the process, while some children in the third grade already have a much larger worldview that helps this other student." The difference of critical consciousness often made a difference in a student's ability to perform in school despite age. While a student may be illiterate, he or she has already learned to "read the world." However, he or she cannot read to make his or her world better economically or socially. This highlights the importance of critical literacy. Knowing how to read is minimal. Employing different literacies in different contexts is fundamental for members of marginalized communities. One teacher expressed, "Literacy is an action. Reading the world is literacy to me. It precedes reading the word. So before I learned to read and write. I saw things. I understood."

\subsection{Self-Efficacy and the Black Consciousness:}

The issue of "Blackness" was central to teachers' self-identity and self-efficacy. For all of the participants, identifying as Afro-Brazilian was a badge of honor instilled in them by their families and communities. While the teachers in this study have opportunities to attend the university and earn a degree, their parents, many of their siblings, and most of their communities lacked access to formal education. Education was not only emphasized as a means of access, but also as responsibility, a way to empower themselves and more importantly, their community. Although it was more important for teachers to impart their knowledge and experiences in the communities where they lived as opposed to investing a large amount of time in the national Black movement in Brazil, teachers felt obligated to teach about their blackness - the richness of Afro-Brazilian history and culture to their students and Brazil. Likewise, these teachers not only identified as being a teacher in the classroom, but also a teacher at church and community organizations. For example, one participant, a pastor of small church in a poor community, identified himself as teacher many years before he entered a teacher education program. Though he did not have formal education, he believed that his role as a teacher and pastor were one in the same, that of a change agent. He stated: "I come from a family of illiterates. My family taught me a great awareness of my citizenship as an Afro-Brazilian. This is the kind of interpretation that leads to the empowerment of individuals in the community. I have great interest in this, and it is my responsibility."

Another teacher also believed in promoting the black consciousness of Afro-Brazilian students who were already marginalized. She stated, "My role as a black teacher is a critical stance in the classroom because my experiences allow me to help students have the same opportunity that I had to be in any other social space, for example, the university." In the context of Brazil, defining blackness is not necessarily easy; conversations about race in Brazil often center on skin color as opposed to ethnicity. Concerning the issue of race, one participant describes her blackness as more of a condition than race. She explains, "I consider myself Black because it identifies my condition and not the melanin in my skin. Black is an Identification of my race. Black in Brazil is always poor. You very rarely find a Black in Brazil with a very favorable condition." When viewing blackness from this perspective, your role as a black teacher is magnified, either to continue the status quo or to work towards improving the condition of blackness.

\subsection{Social Justice through Literacy}

Teachers in this study used their perception of literacy to guide what they believe literacy can do to improve one's life. Stating that they firmly believed in the Freirean philosophy, teachers enacted their beliefs by engaging in dialogic conversations in their classrooms while emphasizing Afro-Brazilian history and culture. 
Participatory citizenship became a requirement in the Freirean based classrooms as social and political awareness claimed the central focus of many lessons. Teachers emphasized students' experiences as a major source of knowledge in the classroom. As a result, teachers created a framework for students to grapple with their literacy knowledge as it related to their social and cultural experiences. Additionally, the Afro-Brazilian experience is part of the Brazilian experience. Having more Afro-Brazilian students and teachers has the potential to strengthen the critical conscientiousness of members in this community and to the Brazilian society as a whole.

\section{Implications \& Conclusions}

The topics and issues discussed in this article have critical implications for the advancement of critical literacy and the progressive implementation of critical pedagogy. However, the findings of this study also yield insights that can guide future research relating to critical pedagogy, particularly when involving Afro-Brazilian teachers and their pedagogical efforts and the relationship between their access to education and sociopolitical/socio cultural involvement. Though these interactions with Afro-Brazilian teachers provide key insights, further research is necessary to understand the complex nature of political and historical contexts in relation to social and cultural experiences as well as the racial and educational identities of Afro- Brazilian teachers. This is important for new ways of thinking about how to educate students as well as to promote teachers who come from marginalized backgrounds. Understanding the history of limited access to education for Afro-Brazilian teachers can strengthen the democratization of education in Brazil. Furthermore, delving more deeply into the impact of equity based programs, such as PARFOR, can add to the needed measures of not only increasing access to education for all, but also to improve the quality of the entire education system, including private and public schools as well as institutions of higher learning.

\section{Acknowledgements}

I gratefully acknowledge the financial support from the Fulbright Scholars Program that made this work possible. I also wish to thank the Universidade Federal da Bahia (FACED-UFBA) for their support of my research and Ms. Amanda Moraes Azevedo for her work with language translation.

\section{Table 1: Research Participants}

\begin{tabular}{|ccccc|} 
Teacher & Gender & Years of Experience & $\begin{array}{c}\text { Teaching } \\
\text { Degree/Certification }\end{array}$ & $\begin{array}{c}\text { Self-Identified } \\
\text { Race/Ethnicity }\end{array}$ \\
\hline S1 & Female & 32 & No & Black \\
S2 & Female & 34 & Yes & Black \\
S3 & Female & 4 & No (Pre-Service) & Black \\
S4 & Male & 3 & No (Pre-Service) & Black \\
S5 & Male & 22 & Yes-Masters & Moreno \\
S6 & Female & 3 & No & Moreno \\
S7 & Male & 5 & Yes-Masters & Moreno \\
\hline
\end{tabular}

Table 2: Classroom Observations Characteristics

\begin{tabular}{|cccc|}
\hline Teacher & Grade Level & Content Area & Student Grouping \\
S1 & $6-8$ & Portuguese Language & Whole Class \\
S2 & K-12 & Special Education & Small Group \\
S3 & $6-12$ & Afro-Brazilian History \& & Small Group/Community \\
& Culture & \\
S4 & Adult & $\begin{array}{c}\text { Afro-Brazilian History \& } \\
\text { Culture/Religion }\end{array}$ & Whole Class/Community \\
S5 & $9-11$ & ESOL & Whole Class \\
S6 & $3-5$ & Portuguese Language & Whole Class \\
S7 & $9-13$ & Portuguese Language & Whole Class \\
\hline
\end{tabular}




\section{References}

Auerbach, E.R. (1989). Toward a social-contextual approach to family literacy. Harvard Educational Review, 108(10), 2080-2114.

Barretto, E. S. S. (2015). Teacher education policies in Brazil: Contemporary challenges. Revista Brasileira de Educacao, 20(62), 679-700.

Bartlett, L. (2005). Dialogue, knowledge, and teacher-student relations: Freirean pedagogy in theory and practice. Comparative Education Review, 49(3), 344-364.

Brazilian Institute for Geography and Statistics (IBGE). (2010). Delpit., L. (2006). Other people's children: Cultural conflict in the classroom. New York: The New Press.

Ekey, V. (2010). The Afro-Brazilian University Experience: How racial quota policy beneficiaries at the Federal University of Bahia perceive racial quota debates, UFBA quota policy, and life as quota students. Independent Study Project (ISP) Collection.

Freire, P. (1993). Pedagogy of the oppresses. New York: Continuum.

Freire, P., \& Macedo, D. (1987). Literacy: Reading the word and the world. Westport, CT: Bergin \& Garvey.

Gee, J.P. (1993). Postmodernism and literacies. In C. Lanshear \& P. McLaren (Eds.), Critical literacy: Politics, praxis, and the postmodern (p. 271-296). Albany, NY: SUNY Press.

Hall, L. A. (2005). Teachers and content area reading: Attitudes, beliefs and change. Teaching and Teacher Education: An International Journal of Research and Studies, 21(4), 403-414.

Htun, Mala. (2004). From racial democracy to affirmative action: Changing state policy on race in Brazil. Latin American Research Review, 39, 60-89.

Lanksheaar, D., \& McLaren, P. (Eds.). (1993). Critical Literacy: Politics, praxis, and the postmodern. Albany, NY: SUNY Press.

Lee, C.D. (2007). Culture, literacy, and learning: Taking bloom in the midst of the whirlwind. New York: Teachers College Press.

Marshall, C. \& Rossman, G.B. (2006). Designing qualitative research. Thousand Oaks, CA: Sage. Merriam, S. B. (2002). Qualitative research in Practice: Examples for discussion and analysis. San Francisco: JosseyBass.

Miles, M. B., \& Hubermann, A. M. (1994). Qualitative data analysis. Thousand Oaks, CA: Sage.

Moje, E. B. (2000). To be a part of the story: The literacy practices of gangsta adolescents. Teachers College Record, 102, 652-690.National Center for the Study of Adult Learning and Literacy. (2007).

Nieto, S. (2006) . Language, literacy, and culture: Intersections and implications. In D.S. Pollard \& O.M. Welch (Eds.), From center to margins: The importance of self-definition in research (pp. 61-86). Albany, New York: SUNY Press.

Instituto o Plano Nacional de Formação de Professores da Educação Básica (PARFOR). (2009). Diário Oficial da União, Brasília, DF: MEC.

Patton, M. Q. (2001). Qualitative evaluation and research methods (2nd ed). Newbury Park, CA: Sage.

Racusen, S. (2009). Affirmative action and identity. In B. Reiter \& G.L. Mitchell (Eds.), Brazil's new racial politics (pp.89-117). Boulder, Colorado: Lynne Reiner Publishers.

Shanahan, T., \& Shanahan, C. (2008). Teaching disciplinary literacy to adolescents: Rethinking content-area literacy. Harvard Educational Review: 78(1), 40-59.

Shor, I. (1992). Empowering education: Critical teaching for social change. Chicago: University of Chicago Press.

Telles, E. (2004). Race in another America: The significance of skin color in Brazil. Princeton, New Jersey: Princeton University Press.

Telles, E. (2007). Racial discrimination and miscegenation. The experience in Brazil. UN Chronicles:44(3).

Yin, R. K. (2003). Case study research: Design and methods. Thousand Oaks, CA: Sage. 